\title{
Lipodystrophy among Children Infected with Human Immunodeficiency Virus and on Antiretroviral Treatment in Ouagadougou
}

\author{
Caroline Yonaba1, Aïssata Ouedraogo ${ }^{2 *}$, Sylvie Armelle Pingwende Ouédraogo², \\ Bourama Ouattara ${ }^{2}$, Angel Kalmogho', Fla Koueta2 ${ }^{2}$, Diarra Yé2, Ludovic Kam1 \\ ${ }^{1}$ Department of Pediatric, Yalgado Ouedraogo University Teaching Hospital, Ouagadougou, Burkina Faso \\ ${ }^{2}$ Department of Pediatric, Charles de Gaulle Pediatric University Teaching Hospital, Ouagadougou, Burkina \\ Faso \\ Email: ${ }^{*}$ sita kab@yahoo.fr
}

Received 17 June 2015; accepted 24 August 2015; published 27 August 2015

Copyright (C) 2015 by authors and Scientific Research Publishing Inc.

This work is licensed under the Creative Commons Attribution International License (CC BY). http://creativecommons.org/licenses/by/4.0/

(c) (7) Open Access

\begin{abstract}
Management of Human Immunodeficiency Virus infection remains a major challenge in many sub-Saharan African countries. Antiretroviral drugs which have reduced significantly the mortality rate of this pandemic disease are a source of side effects. Among these side effects, adult lipodystrophy has already been described by several authors. The aim of this study is to determine the prevalence of lipodystrophy and associate factors in children on antiretroviral therapy, managed at Charles De Gaulle Children University Hospital and Yalgado Ouedrago University Hospital in Ouagadougou, Burkina Faso. This is a cross-sectional study conducted from June 2013 to January 2014. We included children aged 2 to 15 years who had been on antiretroviral treatment for at least six months with no severe acute malnutrition (wasting). Lipodystrophy was diagnosed clinically after assessment of morphological changes. Overall, 323 children complying with the inclusion criteria were examined. The average duration of antiretroviral therapy was $\mathbf{5 . 3}$ years. Forty five children had lipodystrophy, i.e. $13.9 \%$ prevalence rate. One hundred and twenty seven different lipodystrophic lesions were noted, hence $82.7 \%$ lipoatrophy and $17.3 \%$ lipohypertrophy. The most common presentations were: face $(32 \%)$, lower limbs $(26 \%)$ and upper limbs $(15.7 \%)$. Factors associated with lipoatrophy were: age above 10 years $(P=0.004)$; male gender $(P=0.0004)$; antiretroviral treatment duration of more than 60 months $(P<0.001)$ and treatment with stavudine $(P=0.01)$. Our study showed that lipodystrophy is not exceptional in children on antiretroviral therapy in Ouagadougou. However, more researches on lipid profiles of these children are necessary to prevent other common complications related to fat accumulation.
\end{abstract}

\footnotetext{
${ }^{*}$ Corresponding author.
} 


\section{Keywords}

\section{HIV, Children, Lipodystrophy, Burkina-Faso}

\section{Introduction}

Lipodystrophy is a condition characterized by morphological changes due to a disorder in the distribution of fat in Human immune deficient virus (HIV) infected people treated with antiretroviral therapy. It remains a major issue because of the psychosocial stigma [1] and the atherogenic risk [2]-[4].

A prevalence rate of $20 \%$ to $80 \%$ has been reported [5] [6]. Several authors have shown that lipid disorders due to the long term antiretroviral use, notably hypertriglyceridemia and dyslipidemia [6]-[9].

Dollfus et al. in France in 2001 found 13 cases of lipodystrophy in 39 children under antiretroviral therapy. These children were aged 5 to13 years [10].

Piloya et al. in Uganda found in a study including 364 HIV-infected children and under antiretroviral treatment, $27 \%$ of lipodystrophy and 34\% of hyperlipidemia [11].

The European group found through a study including 477 children in 30 pediatric clinics, $26 \%$ of lipodystrophy among which $8.8 \%$ of lipohypertrophy, $7.55 \%$ of lipoatrophy and $9.64 \%$ for the mixed form [12].

Nucleoside inhibitors of the reverse transcriptase are the most responsible of lipodystrophy [2] [13]. In 2013, less toxic regimens were not widely available for children in Burkina Faso [14]. Our aim is to describe lipodystrophy cases and to determine associated factors in children on antiretroviral therapy in two hospitals of Ouagadougou.

\section{Materials and Method}

This is a descriptive and analytical cross-sectional study. We included HIV-infected children on antiretroviral therapy managed as outpatients at Charles De Gaulle University Hospital (CHUP CDG) and Yalgado Ouedraogo University Hospital (CHUYO). The two hospitals together manage a population of 891 HIV infected children and among them 606 were on antiretroviral therapy.

Children who were on antiretroviral therapy for at least 6 months and aged between 2 and 15 years were included. A parent's or tutor's consent was required for all children to participate in the study. We excluded children who had severe malnutrition or other chronic diseases (carditis, kidney failure, tuberculosis, etc.).

Data on clinical symptoms were collected on each medical visit. Weight and height were assessed in order to check for any morphological changes. We paid special attention to fat loss areas (lipoatrophy), notably arms (thinning and decrease in the upper arm circumference), legs (thinning with abnormal visualization of veins), face (widening of cheeks or the temporal region) and buttocks (flattening). Areas of lipohypertrophy or fat accumulation were investigated on the abdomen (increase of the volume with an enlargement of waist size), chest, breast, pelvis, and neck (buffalo hump). Blood pressure assessment at rest completed the examination.

Each child's blood tests of less than 3 months were registered. Blood samples were taken on an empty stomach and then analyzed in each hospital's laboratory. Lipids measurement included only total cholesterol and tryglyceridemia. Antiretroviral treatments at admission and at the time of the survey were registered.

In our study, were analyzed antiretroviral (ARV) regimens those including the start of antiretroviral therapy, zidovudine (AZT), stavudine (D4T) or protease inhibitors (IP). Protease inhibitor available in both hospitals for the monitoring of children was ritonavir-boosted lopinavir (lopi/rt).

Data were entered and processed with Epi Info software, version 3.5.1, SPSS Version 17, Word and Excel 2007. $\mathrm{Chi}^{2}$ statistical test was used to compare variables. Statistical gaps were significant when $\mathrm{P}<0.05$.

Factor analysis consisted in comparing (using $\mathrm{Chi}^{2}$ test) the frequency of some of the characteristics between the group of children with lipodystrophies and those without. These characteristics included age, gender, treatment regimen at admission, the length of the treatment and the WHO clinical level at admission. The same characteristics (except clinical level) were compared for lipoatrophy.

\section{Results}

\subsection{Population Description}

Overall 323 children who met the inclusion criteria were examined. The average age was 9.9 years and 167 of 
them (51.7\%) were above 10 year-old. Male represented 50.2\%.

Children were HIV1 infected in $98.8 \%$ cases $(\mathrm{N}=319)$ and HIV2 in $1.2 \%$ cases $(\mathrm{N}=4)$.

At the initiation of antiretroviral therapy, TCD4 lymphocytes count was available for 135 children, among them 38.5\% had severe immune deficiency (TCD4 lymphocytes rate $<200$ cells $/ \mathrm{mm}^{3}$ ).

Body mass index (BMI) was calculated in 289 children aged above five years and nine of them (3.1\%) were obese (BMI > 30).

One hundred and sixty four (164) children had reached puberty and among them 111 (67\%) were above Tanner stage 2 .

Six children (2.1\%) out of 282 who had their blood pressure checked, were found to have high blood pressure.

The average duration of antiretroviral therapy was 55.9 months \pm 15 months with extremes of 7 and 121 months.

All the patients were on Highly Active Antiretroviral Therapy (HAART). First line treatments included the association of "zidovudine-lamivudine-nevirapine" or "stavudine-lamivudine-nevirapine" respectively in $34.7 \%$ and $30.7 \%$ of our patients.

Other characteristics of children on antiretroviral treatment are listed in Table 1.

At the time of the survey, among 152 children who had their blood tests available, hyperglycemia (>7.1 mmol/l) was noted in 3 children (2\%); total hypercholestérolemia ( $>4.5 \mathrm{mmol} / \mathrm{l})$ in 9 children $(6 \%)$ and hypertrigly-ceridemia ( $>1.55 \mathrm{mmol} / \mathrm{l})$ in 12 children $(7.9 \%)$.

Lipodystrophy was found in 45 (13.9\%) children out of 323 examined, among them 29 (62.2\%) were male.

\subsection{Types and Locations of Lipodystrophy}

Among 45 children who had lipodystrophy, 10.8\% had lipoatrophy, 1.9\% had mixed type and $1.2 \%$ had lipohypertrophy.

Several locations of lipodystrophy were noticed. Some of the children presented more than one location. On the whole, 127 lesions were found in 45 children, including $82.7 \%$ of lipoatrophy and $17.3 \%$ of lipohypertrophy.

Table 2 summarizes the distribution of lipodystrophy per type and location.

The face and limbs (upper and lower) were the most common locations both for lipodystrophy and lipoatrophy.

Table 1. General characteristics of 323 children on antiretroviral therapy.

\begin{tabular}{|c|c|c|}
\hline Characteristics & Number (n) & Percentage (\%) \\
\hline \multicolumn{3}{|l|}{ Age (years) } \\
\hline$\leq 10$ & 156 & 48.3 \\
\hline$>10$ & 167 & 51.7 \\
\hline \multicolumn{3}{|c|}{ WHO Clinical stage* } \\
\hline Stage 1 & 3 & 0.9 \\
\hline Stage 2 & 61 & 18.9 \\
\hline Stage 3 & 234 & 72.5 \\
\hline Stage 4 & 25 & 7.7 \\
\hline \multicolumn{3}{|l|}{ Social status } \\
\hline Orphan $^{* *}$ & 210 & 65.0 \\
\hline Non orphan & 113 & 35.0 \\
\hline \multicolumn{3}{|l|}{ Treatment duration } \\
\hline$\leq 60$ mois & 189 & 58.5 \\
\hline$>60$ mois & 134 & 41.5 \\
\hline \multicolumn{3}{|c|}{ Initial Treatment regimen } \\
\hline $\mathrm{AZT}+$ & 178 & 55.2 \\
\hline $\mathrm{D} 4 \mathrm{~T}+$ & 139 & 43.0 \\
\hline Other regimens & 6 & 1.8 \\
\hline
\end{tabular}

"WHO 2013 Classification, ${ }^{* *}$ orphan of one or two parents. $(\mathrm{AZT}+)=$ regimen containing zidovudine $(\mathrm{AZT}),(\mathrm{D} 4 \mathrm{~T}+)$ ) regimen containing stavudine (D4T). 
Table 2. Distribution of lipodystrophy per type of location.

\begin{tabular}{ccccc}
\hline Locations & Lipoatrophy & Lipohypertrophy & Number (n) & Percentage (\%) \\
\hline Face & 41 & 0 & 41 & 32.2 \\
Lower limbs & 33 & 0 & 33 & 26.0 \\
Upper limbs & 20 & 0 & 20 & 15.7 \\
Buttocks & 10 & 2 & 12 & 9.4 \\
Abdomen & 0 & 10 & 10 & 7.9 \\
Breast & 0 & 5 & 5 & 4.0 \\
Brain area & 1 & 2 & 3 & 2.4 \\
Pubis & 0 & 3 & 3 & 2.4 \\
\hline
\end{tabular}

\subsection{ART Regimens of Children Presenting with Lipodystrophy}

Among the children presenting with lipodystrophy, 35 (77.8\%) started their treatment with D4T and 9 (20\%) with AZT. At the time of the survey, AZT was used in $34(75.6 \%)$ patients, D4T in four (8.9\%) patients and protease inhibitors in 12 (26.7\%).

\subsection{Associated Factors}

We studied on one hand, the association between lipodystrophy and some of the clinical and therapeutic factors, and on the other hand, the association between lipoatrophy and the same factors listed above. Results are shown on Table 3 and Table 4.

The frequency of lipoatrophy was significantly higher in patients whom antiretroviral treatment duration was more than 60 months and those whose treatment included stavudine.

\section{Discussion}

Patients' mean age was 9.9 years. This was also the case for Piloya in Uganda, Dollfus in France and Vigano in Italy, who recorded a mean age of 9.8 years; 9.1 years and 9.78 years in their studies respectively [10] [11] [15].

Inefficient programs for the prevention of mother-to-child transmission of HIV (PMTCT) may explain our results. The extension of the PMTCT program started in 2006 in Burkina Faso. Therefore, the majority of children born before 2006 did not benefit from this program; this accounts for the predominance of above 10 year-old patients in our study.

The first line treatment used in our study is that recommended in Burkina Faso [14].

AZT and D4T have long been the basis of the first line antiretroviral treatment in most developing countries. The process of switching D4T to AZT was done in keeping with D4T switching plan recommended by World Health Organization (WHO) in 2010 [16].

To reduce the occurrence of new cases of lipodystrophy this process must be accelerated in our hospitals.

Lipodystrophy prevalence rate (13.9\%) was fairly high in our study.

The European Group of Pediatric lipodystrophy had reported a prevalence rate of $26 \%$ in France, including 7.5\% for lipoatrophy, $8.8 \%$ for lipohypertrophy and $9.6 \%$ for the mixed syndrome in a prospective study covering 477 HIV infected children [12].

Piloya in Uganda found a prevalence rate of $27 \%$ of lipodystrophy in 364 HIV infected children [11]. However, Kinabo et al. in Tanzania reported lipodystrophy prevalence rate of 30\%, including 19\% for lipoatrophy, 3.8\% for lipohypertrophy and 7.1\% for mixed forms in a cross-sectional study on $210 \mathrm{HIV}$ infected children and adolescents aged 1 to 18 years [17].

The prevalence of lipodystrophy therefore varies from one study to another. In all these three researches mentioned above, study design included adolescents aged 18 years in whom the risk of occurrence of lipodystrophy is higher than that of under 15 years [5] [10] [11]. Other diagnostic methods are more accurate and should be used whenever possible; skin fold measurement or muscles Dexa-scan and body fat assessment [18] [19].

In our series, several locations of lipodystrophy were found including $32 \%$ in the face, $26 \%$ on the lower limbs. Our results are similar to those of Joly in France who found $49 \%$ and $48 \%$ of locations on the face and lower limbs [13]. 
Table 3. Factors associated with lipodystrophy.

\begin{tabular}{|c|c|c|c|c|c|}
\hline \multirow[b]{2}{*}{ Associated factors } & \multirow[b]{2}{*}{ Number } & \multicolumn{2}{|c|}{ Lipodystrophy } & \multirow{2}{*}{$\begin{array}{c}\text { Odds ratio } \\
\text { (IC) }\end{array}$} & \multirow[b]{2}{*}{$\mathrm{P}$} \\
\hline & & $\begin{array}{l}\text { Yes } \\
\text { N (\%) }\end{array}$ & $\begin{array}{c}\text { No } \\
\text { N (\%) }\end{array}$ & & \\
\hline $\begin{array}{l}\text { Age (years) } \\
\quad \leq 10 \\
\quad>10\end{array}$ & $\begin{array}{l}156 \\
167\end{array}$ & $\begin{array}{l}15(9.6) \\
30(18)\end{array}$ & $\begin{array}{c}141(90.4) \\
137(82)\end{array}$ & $\begin{array}{c}1 \\
0.5(0.3-1)\end{array}$ & 0.005 \\
\hline $\begin{array}{l}\text { Sex } \\
\text { Female } \\
\text { Male }\end{array}$ & $\begin{array}{l}161 \\
162\end{array}$ & $\begin{array}{l}17(10.6) \\
28(17.3)\end{array}$ & $\begin{array}{l}144(89.4) \\
134(82.7)\end{array}$ & $\begin{array}{c}1 \\
1(0.9-1.1))\end{array}$ & 0.042 \\
\hline \multicolumn{6}{|l|}{ Clinical stage } \\
\hline 1 & 2 & $1(50)$ & $1(50)$ & 1 & \\
\hline 2 & 62 & $3(4.8)$ & $59(95.2)$ & $7.5(5.2-9.4)$ & 0.5 \\
\hline 3 & 233 & 39 (16.7) & 194 (83.3) & $0.3(0.2-0.8)$ & 0.001 \\
\hline 4 & 26 & $2(7.7)$ & $24(92.3)$ & $2.4(0.9-5.5)$ & 0.06 \\
\hline \multicolumn{6}{|l|}{$\begin{array}{c}\text { Treatment duration } \\
\text { ARV }\end{array}$} \\
\hline$\leq 60$ & 189 & $12(6.3)$ & 177 (93.7) & 1 & \\
\hline$>60$ & 134 & $33(24.6)$ & $101(75.4)$ & $0.4(0.2-0.7)$ & $<0.001$ \\
\hline \multicolumn{6}{|l|}{ Initial treatment regimen } \\
\hline AZT- & 145 & $36(24.8)$ & $109(75.2)$ & 1 & \\
\hline $\mathrm{AZT}+$ & 178 & $9(5)$ & $169(95)$ & $6.3(0.2-8.2)$ & 0.41 \\
\hline D4T- & 184 & $10(5.4)$ & $174(94.6)$ & 1 & \\
\hline $\mathrm{D} 4 \mathrm{~T}+$ & 139 & $35(25.2)$ & $104(74.8)$ & $0.2(0.1-0.3)$ & $<0.001$ \\
\hline Lopi/rt- & 271 & $33(12.2)$ & $238(87.8)$ & 1 & \\
\hline Lopi/rt+ & 52 & $12(23)$ & $40(77)$ & $0.4(0.2-0.6)$ & 0.06 \\
\hline
\end{tabular}

$(\mathrm{AZT}-)=$ Treatment regimen not containing zidovudine; $(\mathrm{AZT}+)=$ Treatment regimen containing zidovudine; $(\mathrm{D} 4 \mathrm{~T}-)=$ Treatment regimen not containing zidovudine; $(\mathrm{D} 4 \mathrm{~T}+)=$ Treatment regimen containing stavudine; $($ Lopi/rt -$)=$ Treatment regimen not containing lopinavir/ritonavir; $($ Lopi/rt +$)=$ Treatment regimen containing lopinavir/ritonavir.

Table 4. Factors associated with the presence of lipoatrophy.

\begin{tabular}{|c|c|c|c|c|c|}
\hline \multirow{2}{*}{ Associated factors } & \multirow{2}{*}{ Number } & \multicolumn{2}{|c|}{ Lipodystrophy } & \multirow{2}{*}{$\begin{array}{c}\text { Odds ratio } \\
\text { (CI) }\end{array}$} & \multirow{2}{*}{$\mathrm{P}$} \\
\hline & & Yes N (\%) & No N (\%) & & \\
\hline \multicolumn{6}{|l|}{ Age (years) } \\
\hline$\leq 10$ & 156 & $11(7)$ & $145(93)$ & 1 & \\
\hline$>10$ & 167 & $24(14.4)$ & $143(85.6)$ & $0.5(0.3-1)$ & 0.004 \\
\hline $\begin{array}{c}\text { Sex } \\
\text { Female } \\
\text { Male }\end{array}$ & $\begin{array}{l}161 \\
162\end{array}$ & $\begin{array}{c}8(5) \\
27(16.7)\end{array}$ & $\begin{array}{c}153(95) \\
135(83.3)\end{array}$ & $\begin{array}{c}1 \\
0.3(0.2-0.6)\end{array}$ & 0.0004 \\
\hline \multicolumn{6}{|c|}{ Treatment duration (month) } \\
\hline$\leq 60$ & 189 & $8(4.2)$ & $181(95.8)$ & 1 & \\
\hline$>60$ & 134 & $27(2)$ & $107(98)$ & $0.2(0.1-0.3)$ & $<0.001$ \\
\hline \multicolumn{6}{|l|}{ Initial treatment } \\
\hline $\mathrm{AZT}-$ & 145 & $30(2)$ & $115(98)$ & 1 & \\
\hline $\mathrm{AZT}+$ & 178 & $5(2.8)$ & $173(97.2)$ & $8.6(5.8-9.8)$ & 0.49 \\
\hline D4T- & 184 & $6(3.3)$ & $178(96.7)$ & 1 & \\
\hline D4T+ & 139 & $29(2)$ & $110(98)$ & $0.1(0.09-0.2)$ & 0.01 \\
\hline
\end{tabular}


On the contrary, the European Group of Pediatric Lipodystrophy found that the trunk was the most affected area in $66 \%$ of cases, followed by the lower limbs, the face, the upper limbs, the buttocks in $40 \%$; $39 \%$; $37 \%$ and $22 \%$ of cases respectively [12].

The development of lipodystrophy and especially lipoatrophy may be a source of stigma. Likewise, patients who link lipodystrophy to antiretroviral do not usually adhere to that treatment [12].

Lipoatrophy treatment is not well codified which makes it difficult for patients to get appropriate care. In adults, medical treatment with statines or plastic surgery has provided contradictory results [6] [20]. In our working context, psychological support remains the sole accessible solution. At the time of the survey, the national plan to switch D4T to other less toxic regimens was still underway.

In univariate and multivariate analysis, age above 10 years was significantly associated with lipodystrophy $(P=0.005)$. This result is similar to that found by other authors [10] [12] [17]. Morphological changes therefore increase with age.

Contrary to our study, Aurpibul in Thailand had noticed that lipodystrophy was more common in girls than boys, $61 \%$ and $39 \%$ of cases respectively [5]. Actually, there are seemed to be gender-based physiological differences in the occurrence of lipodystrophy. At puberty, estrogen and progesterone hormones contribute to fat accumulation in girls whereas in boys, testosterone, an anabolic hormone, maintains little fat accumulation. Thus, lipohypertrophy should normally be expected to be more common in girls than boys. However this was not the case in our study, the frequency of lipoatrophy among boys (16.7\%) was higher than that of girls (5\%) $(\mathrm{P}=0.004)$.

We found no connection between hypercholesterolemia, hypertriglyceridemia, hyperglycemia and the presence of lipodystrophy in children. We think that these biological disturbances were transient and not associated with metabolic syndrome.

Lipodystrophy was found in all antiretroviral therapy regimens in our series. AZT and D4T of Nucleoside Reverse Transcriptase Inhibitors class (NRTIs), historically linked to lipodystrophy, and were used in $20 \%$ and $77.8 \%$ of our patients with lipodystrophy. Our results are very similar to those of Dollfus et al. who found that D4T was used in 92\% of patients presenting lipodystrophy compared to 42\% for AZT [10].

We found that D4T was significantly associated with the presence of lipodystrophy $(\mathrm{P}<0.001)$ and especially lipoatrophy $(\mathrm{P}=0.01)$. Our results are similar to those of Viard in France who, in a randomized trial on D4T and risk of lipoatrophy, found 3.6 times higher the risk of developing lipoatrophy when using D4T than AZT [13].

NRTIs particularly thymidinic derivatives (D4T and AZT), have a direct impact on mitochondria. They decrease the mitochondrial DNA and the respiratory chain proteins and increase the production of reactive oxygen. D4T and AZT induce lipolysis and, under certain circumstances, an apoptosis of adipocytes. These molecules interfere with adipocyte differentiation and contribute to activate the production of pro-inflammatory cytokines; while the other NRTIs do not change the rate of the mitochondrial DNA significantly [2].

Proteases inhibitors used in ARV regimen were found in $26.7 \%$ of patients presenting with lipodystrophy, this rate is lower than that found by Dollfus et al. of 79\% [10]. In statistical analysis, there was no link between an exposure to PIs and the development of lipodystrophy $(\mathrm{P}=0.06)$. However, some authors found a statistically significant link between exposure to PIs and the occurrence of lipodystrophy [17]. Indeed, protease inhibitors are associated with an alteration of the adipocyt differentiation, an oxidative stress and the production of pro-inflammatory cytokines.

\section{Limits for This Study Were}

- The method used to diagnosis lipodystrophy (morphological change) might have under estimated the disorder.

- The study was conducted in two hospitals of Ouagadougou and might not represent the profile of all HIV infected children on antiretroviral therapy in Burkina Faso.

\section{Conclusion}

We found a high prevalence rate of lipodystrophy in HIV-infected children on antiretroviral treatment. Age older than 10 years, WHO clinical stage 3, and long-term exposure to antiretroviral treatment especially D4T were factors most associated with lipoatrophy. Our results highlight the need to make available less toxic antiretroviral drugs for pediatric population. We'll have to try and make health professionals aware of screening for lipodystrophy. More researches on larger cohort in our setting are necessary to determine other metabolic disorders 
and associated factors in HIV-infected children treated with antiretroviral.

\section{References}

[1] Mutimura, E., Stewart, A. and Crowther, N.J. (2007) Assessment of Quality of Life in HAART-Treated HIV-Positive Subjects with Body Fat Redistribution in Rwanda. AIDS Research and Therapy, 4, 19. http://dx.doi.org/10.1186/1742-6405-4-19

[2] Capeau, J., Caron, M., Vigouroux, C., Carvera, P., Kim, M., Maachi, M., et al. (2006) Les lipodystrophy secondaires aux traitements ARV de l'infection par le VIH. Médecine Sciences, 22, 531-536. http://dx.doi.org/10.1051/medsci/2006225531

[3] Mercier, S., Gueye, N.F.N., Cournil, A., Fontbonne, A., Copin, N., Ndiaye, I., et al. (2009) Lipodystrophy and Metabolic Desorders in HIV-1-Infected Adults on 4- to 9-Year Antiretroviral Therapy in Senegal: A Case Control Study. Journal of Acquired Immune Deficiency Syndromes, 51, 224-230. http://dx.doi.org/10.1097/QAI.0b013e31819c16f4

[4] Thiébaut, R., Daucourt, V., Mercié, P., Ekouévi, D.K., Malvy, D., Morlat, P., et al. (2000) Lipodystrophy, Metabolic Disorders, and Human Immunodeficiency Virus Infection: Aquitaine Cohort. Clinical Infectious Diseases, 31, 14821487. http://dx.doi.org/10.1086/317477

[5] Aurpibul, L., Puthanakit, T., Lee, B., Mangtaburks, A., Sirisanthana, T. and Sirisanthana, V. (2007) Lipodystrophy and Metabolic Changes in HIV-Infected Children on Non-Nucleoside Reverse Transcriptase Inhibitor-Based Antiretroviral Therapy. Antiviral Therapy, 12, 1247-1254.

[6] Capeau, J. and Valantin, M.-A. (2011) Syndrome lipodystrophique au cours du traitement antirétroviral in HIV; édition doin. 525-540.

[7] Chironi, G., Simon, A. and Vittecoq, D. (2004) Le risque cardiovasculaire au cours des traitements ARV, effets indésirables et alternatives thérapeutiques. Médecine Thérapeutique, 10, 120-128.

[8] Lapphra, K., Vanprapar, N., Phongsmart, W., et al. (2005) Dyslipidemia and Lipodystrophy in HIV-Infected Thai Children on Highly Active Antiretroviral Therapy (HAART). Journal of the Medical Association of Thailand, 88, 956965.

[9] Hammond, E. and Noland, D. (2007) Adipose Tissue Inflammation and Altered Adipokine and Cytokine Production. Antiretroviral Therapy-Associated Lipodystrophy, 2, 274-281.

[10] Dollfus, C., Jaquet, D., Levine, M., Ortoga-Rodriguez, E., Faye, A., Polak, M., et al. (2000) Clinical and Metabolic Presentation of the Lipodystrophic Syndrome in HIV-Infected Children. AIDS, 14, 2123-2128. http://dx.doi.org/10.1097/00002030-200009290-00008

[11] Piloya, T., Bakeera-Kitaka, S., Kekitiinwa, A. and Kamya, M.R. (2012) Lipodystrophy among HIV-Infected Children and Adolescents on Highly Active Antiretroviral Therapy in Uganda: A Cross Sectional Study. Journal of International AIDS Society, 15, 17427. http://dx.doi.org/10.7448/IAS.15.2.17427

[12] European Paediatric Lipodystrophy Group (2004) Antiretroviral Therapy, Fat Redistribution and Hyperlipidaemia in HIV-Infected Children in Europe. AIDS, 18, 1443-1435. http://dx.doi.org/10.1097/01.aids.0000131334.38172.01

[13] Joly, V., Flandre, P., Meiffredy, V., Leturgue, N., Harel, M., Aboulker, J.P., et al. (2002) Increased Risk of Lipoatrophy under Stavudine in HIV-1-Infected Patients: Results of a Substudy from a Comparative Trial. AIDS, 16, 24472454. http://dx.doi.org/10.1097/00002030-200212060-00010

[14] Ministère de la santé du Burkina Faso (2009) Comité ministériel de lutte contre le VIH/SIDA au Burkina Faso, normes et protocoles de prise en charge médicale des personnes vivant avec le VIH au Burkina Faso. 200 p.

[15] Vigano, A., Mora, S., Testolin, C., Beccio, S., Schneider, L., Bricalli, D., et al. (2003) Increased Lipodystrophy Is Associated with Increased Exposure to HAART in HIV-Infected Children. Journal of AIDS, 32, 482-489. http://dx.doi.org/10.1097/00126334-200304150-00003

[16] WHO (2014) Antiretroviral Therapy for HIV Infection in Infants and Children. http://www.who.int/hiv/pub/paediatric/infants2010/en/

[17] Kinabo, G.D., Sprengers, M., Msuya, L.J., Shayo, A.M., Van Asten, H., Dolmans, W.M., et al. (2012) Prevalence of Lipodystrophy in HIV-Infected Children in Tanzania on Highly Active Antiretroviral Therapy. The Pediatric Infectious Disease Journal, 32, 39-44.

[18] Hartman, K., Verweel, G., Groot, R. and Hartwig, N.G. (2006) Detection of Lipoatrophy in Human Immunodeficiency Virus-1-Infected Children Treated with HAART. The Pediatric Infectious Disease Journal, 25, 427-431. http://dx.doi.org/10.1097/01.inf.0000215003.32256.aa

[19] Padilla, S., Gallego, J.A., Masia, M. and Gutierrez, F. (2004) Single-Slice Computed Tomography and Antropometric Skinfold Analysis for Evaluation of Facial Lipoatrophy in HIV-Infected Patients. Clinical Infectious Diseases, 39, 
1848-1851. http://dx.doi.org/10.1086/426072

[20] Levan, P., Nguyen, T.H., Lallemand, F., Mazetier, L., Mimoun, M., Rozenbaum, W., et al. (2002) Correction of Facial Lipoatrophy, in HIV-Infected Patients on HAART by Injection of Autologous Fatty Tissue. AIDS, 16, 1985-1987. http://dx.doi.org/10.1097/00002030-200209270-00026 